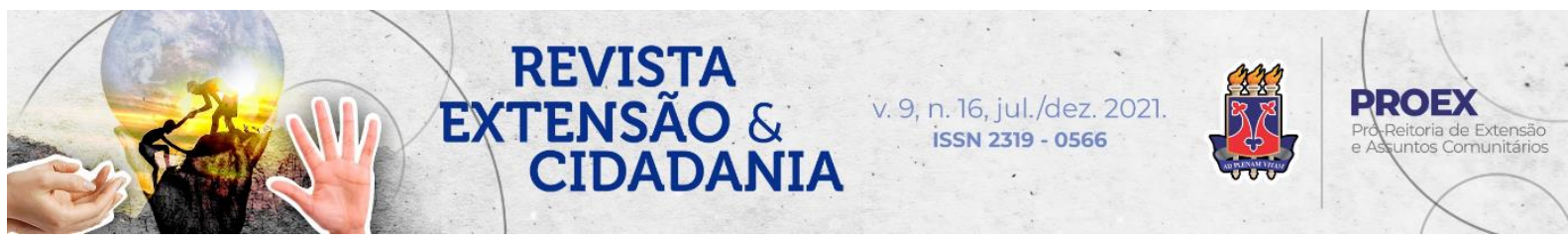

DOI: $10.22481 /$ recuesb.v9i16.8690

\title{
APRENDER ESPANHOL COM CANÇÕES: RELATO DE EXPERIÊNCIA DE UM CURSO DE ESPANHOL ONLINE
}

\section{LEARNING SPANISH WITH SONGS: EXPERIENCE REPORT OF AN ONLINE SPANISH COURSE}

\section{APRENDER ESPAÑOL CON CANCIONES: RELATO DE EXPERIENCIA DE UN CURSO DE ESPAÑOL EN LÍNEA}

Fabiana Brandão Silva Amorim ${ }^{1}$

\begin{abstract}
Resumo: Este relato de experiência refere-se às atividades desenvolvidas dentro do projeto de extensão intitulado "Canta Conmigo - aprender espanhol com canções", realizado por meio das ações extensivas da PROEX-UESB. A utilização de canções para a aprendizagem do espanhol revelou-se uma ferramenta eficaz, a qual também oportuniza o contato com aspectos socioculturais dos países hispanófonos, de forma lúdica e agradável. Aprender a língua através das canções propicia, ademais, um contato prazeroso entre o estudante e a língua que está aprendendo, e esse prazer é fundamental para uma aprendizagem rica e efetiva. Partindo de uma perspectiva comunicativa do ensino de línguas, os componentes sociocultural e sociolinguístico tiveram especial atenção durante a realização dos encontros. Com um total de dez canções uma a cada encontro - os/as estudantes entraram em contato com a língua espanhola seguindo uma sequência didática que foi do nível A1 ao A2, níveis iniciais, segundo o Marco Comum Europeu de Referência (MCER). Dessa forma, tanto os conteúdos linguísticos quanto os comunicativos foram explorados, dando à aprendizagem um entorno significativo e afetivo, $\mathrm{o}$ qual vincula aquilo que se aprende a experiências duradouras e positivas.
\end{abstract}

Palavras-chave: Espanhol. Ensino de línguas. Canções. Espanhol comunicativo.

Abstract: This article aims to report the experience of the extension course "Sing with me learning Spanish with songs", offered by PROEX-UESB. The songs are a good tool for Spanish learning, which also oportunizes the contact with sociocultural aspects of the hispanophone countries, in a ludic and delectable way. Learning a language with songs offers a pleasant contact for the student with that language, and this pleasure is fundamental for a rich and effective learning. From a communicative perspective of language teaching, the sociocultural and the sociolinguistic components had special attention during the course meetings. With ten songs - one for each session - the students had the contact with the Spanish, following the didactical sequence from the level A1 to the A2 - basic users, according to the Common

\footnotetext{
${ }^{1}$ Graduada em Letras/Espanhol e Mestra em Estudos Literários, ambos pela Faculdade de Letras, da Universidade Federal de Minas Gerais (FALE/UFMG). Coordenadora do Projeto de extensão "Canta Conmigo: aprender espanhol com canções". Professora de Língua e Literatura Latinas, da Universidade Estadual do Sudoeste da Bahia (UESB), Campus de Jequié, Bahia, Brasil. Orcid: https://orcid.org/0000-0001-9389-766X E-mail: fabiana.amorim@uesb.edu.br
} 
European Framework of Reference for Languages (CEFRL). This way, linguistic and also communicative contents were exploited, which gave to learning process a significant and affective environment and what students learn is linked to positive and lasting experiences.

Keywords: Spanish. Language teaching. Songs. Communicative Spanish.

Resumen: Este relato de experiencia se refiere a las actividades desarrolladas dentro del proyecto de extensión intitulado "Canta Conmigo - aprender español con canciones", llevado a cabo por medio de las acciones extensivas de la PROEX-UESB. La utilización de canciones para el aprendizaje del español se ha revelado una herramienta eficaz, la cual también permite el contacto con aspectos socioculturales de los países hispanohablantes, de manera lúdica y agradable. Aprender la lengua a través de las canciones propicia, además, un contacto placentero entre el/la estudiante y la lengua que está aprendiendo, y dicho placer es fundamental para un aprendizaje rico y efectivo. Partiendo de una perspectiva comunicativa de la enseñanza de lenguas, los componentes sociocultural y sociolingüístico tuvieron especial atención durante la realización de los encuentros. Con un total de diez canciones - una en cada encuentro - los/las estudiantes entraron en contacto con la lengua española siguiendo una secuencia didáctica que fue del nivel A1 al A2, niveles iniciales según el Marco Común Europeo de Referencia (MCER). De esa manera, tanto los contenidos lingüísticos como los comunicativos han sido explotados, dándole al aprendizaje un entorno significativo y afectivo, lo cual vincula aquello que se aprende a experiencias duraderas y positivas.

Palabras clave: Español. Enseñanza de lenguas. Canciones. Español comunicativo.

\section{Introdução}

Quando idealizamos o Projeto de Extensão “Canta Conmigo - aprender espanhol com canções", partimos da constatação de que aprender uma língua estrangeira é parte das necessidades laborais e acadêmicas de muitas pessoas em nosso entorno. Muitas vezes, esse desejo não é alcançado, porque trata-se de um investimento oneroso e, ao ofertar um curso de espanhol através de canções, estávamos conscientes de que havia uma demanda dentro e fora da comunidade da universidade e de que poderíamos colaborar para sanar essa necessidade.

O campus da Universidade Estadual do Sudoeste da Bahia (UESB), na cidade de Jequié, possui apenas o curso de Letras Vernáculas e, em alguns cursos, é oferecida a disciplina Inglês Instrumental. O conhecimento de outros idiomas, como o espanhol, revela-se como um desejo, já que permite ao público da universidade - especialmente docentes e discentes - e ao da comunidade externa o contato com uma língua adicional e as suas culturas. Ademais, em geral, os cursos oferecidos em escolas de idiomas são pouco acessíveis à comunidade, sobretudo na atualidade, quando o ensino da língua espanhola se viu limitado pela revogação, em 2017, da chamada Lei do Espanhol, Lei n ${ }^{\circ} 11.161$ (BRASIL, 2005), segunda a qual o ensino da língua

Revista Extensão \& Cidadania, v. 9, n. 16, p. 112-122, jul./dez. 2021. 
espanhola era de oferta obrigatória pela escola nos currículos plenos dos anos finais do ensino fundamental e no ensino médio, o que diminuiu a oferta de aulas de espanhol.

A língua espanhola é falada em todos os países com os quais o Brasil faz fronteiras, e essa proximidade geopolítica se traduz em interesse e necessidade de conhecer a língua falada pelos nossos vizinhos. O ensino e a aprendizagem de uma língua estrangeira nos colocam diante da necessidade de, além do conhecimento linguístico e pragmático, também oferecer/ter acesso à(s) cultura(s) que acolhe(m) essa língua e são, ao mesmo tempo, influenciadas por ela.

Uma das formas mais usuais de acesso a esses elementos é a utilização de canções para a sua aprendizagem, pois, além de ser uma eficaz ferramenta no conhecimento da língua espanhola, essa prática oportuniza o contato com aspectos culturais dos países hispanófonos, de forma lúdica, agradável e perene. Por essas razões, o projeto se chama "Canta Conmigo aprender espanhol com canções". Este projeto teve como motivação inicial ampliar este espaço de aprendizagem da língua espanhola, e incluir alunos dos cursos mais diversos, servidores da própria Instituição, bem como profissionais e estudantes da educação básica da rede pública, integrantes de movimentos sociais e de grupos comunitários.

O curso foi idealizado para acontecer dentro do semestre letivo 2019.2, mas, devido à suspensão das atividades acadêmicas da UESB em decorrência da pandemia da Covid-19, foi necessário ofertá-lo totalmente à distância. Esse ajuste possibilitou a sua realização mesmo antes do início do Ensino Remoto Emergencial (ERE) da UESB, e, além disso, propiciou a participação de pessoas de diferentes localidades: a princípio, o curso havia sido idealizado para pessoas da comunidade de Jequié, no entanto, ele ultrapassou os limites do município.

O uso de canções e, consequentemente, da música para a aprendizagem de uma língua estrangeira é um recurso que está amplamente documentado, e seus benefícios na aprendizagem são incontestáveis, como nos faz notar García:

Nos detendremos en las ventajas que comporta esta práctica deteniéndonos en los beneficios de llevar canciones al aula para el desarrollo de la comprensión auditiva y de la lectora. Se verá la importancia que tienen la emoción y el sentimiento en los procesos cognitivos y cómo a través de la música se puede favorecer y provocar el sentimiento de identificación tanto con su mundo interior como con su propia cultura. (GARCÍA, 2013, p. 1)

Num curso regular de língua espanhola, as canções são um recurso utilizado de modo recorrente, seja como apoio a algum conteúdo sociolinguístico, seja como forma de agregar conhecimento sociocultural. Aprender a língua através das canções propicia, também, um

Revista Extensão \& Cidadania, v. 9, n. 16, p. 112-122, jul./dez. 2021. 
contato prazeroso entre o/a estudante e a língua que está aprendendo, e esse prazer é fundamental para uma aprendizagem significativa e efetiva. A aprendizagem através de canções pode levar o indivíduo a produzir o hormônio responsável pelo prazer, como nos mostra Warner apud Moleiro:

Está empiricamente demonstrado que ouvir determinadas composições musicais liberta no cérebro um neurotransmissor, a dopamina, que envia sinais de prazer para o resto do corpo. A dopamina é uma substância que interfere no sistema cerebral e, frequentemente, está associada a prazeres concretos, como a comida, as drogas e o dinheiro. Assim, quanto mais agradável for a música para o ouvinte, melhor será a experiência fisiológica. Experiências levadas a cabo no campo da Medicina constataram que, quando submetidos a composições que suscitavam emoções, os pacientes revelavam alterações na respiração e na frequência de batimentos cardíacos. Essas experiências mostraram também que o mero anúncio, aos participantes, de que iam ouvir música do seu agrado, era suficiente para libertar elevados níveis de dopamina. (WARNER apud MOLEIRO, 2011, p. 25)

Sem sombra de dúvidas, o componente "prazer em aprender" faz parte das aulas de um curso de idiomas projetado com canções. Os encontros são cheios de alegria e de vitalidade, os/as estudantes participam ativamente de tudo que lhes é proposto. Conhecem ritmos e cantores novos, e a língua lhes é oferecida através de um material real e vivo, criado cultural e historicamente: a música. A música é parte do patrimônio cultural dos seus países, algumas são parte do cancioneiro tradicional e, mesmo pertencendo a países estrangeiros, conseguem nos tocar e deixar seu legado, seja ele linguístico ou cultural. Segundo Nina Kraus apud Moleiro:

[...] o efeito da música no cérebro, à semelhança da influência do exercício físico no corpo humano, "tones the brain for auditory fitness". Neste estudo, a autora reflecte sobre efeitos da música no sistema nervoso e as suas implicações no campo da educação. Kraus chega à conclusão de que as crianças habituadas a escutar música são mais fluentes no seu discurso, no vocabulário que usam e na sua capacidade para interpretar textos de variados tipos. Considerando a influência da música no processo de aprendizagem, muitos teóricos acreditam que devia prestar-se mais atenção, tanto na investigação como nas suas aplicações, à interferência da música nos alunos e aos seus efeitos na compreensão, memória, atenção e níveis de literacia. (KRAUS, 2010 apud MOLEIRO, 2011, p. 27)

De posse da compreensão sobre a relação entre a música e a aprendizagem humana, passamos a conhecer um pouco como funcionou o curso Canta Conmigo. O curso tinha os seguintes objetivos: a) despertar o interesse do aluno pela língua espanhola, desenvolvendo, principalmente, as habilidades de compreensão auditiva e de leitura; b) fazer com que o aluno fosse capaz de reconhecer estruturas gramaticais do espanhol e de utilizá-las em situações de

Revista Extensão \& Cidadania, v. 9, n. 16, p. 112-122, jul./dez. 2021 
comunicação; c) despertar no aluno uma maior consciência sobre a(s) cultura(s) ligada(s) à língua espanhola, em suas diversas variantes regionais, bem como o papel das línguas na sociedade.

O interesse dos/das estudantes pela disciplina espanhol havia sido o que os/as havia levado a inscrever-se no curso, portanto, não cremos que fosse necessário ter que despertá-lo. E fazê-lo com o uso das canções criou, naturalmente, a habilidade da compreensão auditiva, que foi aplicada através de diferentes exercícios de identificação de sons e de palavras. Conhecer e reconhecer estruturas gramaticais é um processo que leva mais tempo de maturação, mas que foi bem sucedido de acordo com o que foi solicitado aos/às estudantes. E, finalmente, cremos que a consciência acerca da relação entre a língua espanhola e as diversas culturas que a compõem se realizou. Podemos afirmar que todos os objetivos foram alcançados e que a proposta inicial, que era ensinar certos conceitos da língua espanhola, foi desenvolvida.

A inscrição dos candidatos se deu por meio de formulário do Google e a seleção obedeceu a dois critérios isonômicos e complementares: a) a ordem de inscrição; e b) a proporcionalidade no número de vagas $-50 \%$ das vagas destinadas à comunidade interna da UESB, 50\% das vagas destinadas à comunidade externa. Na ausência de candidatos que atendessem aos números da proporcionalidade "comunidade interna/comunidade externa da UESB", a ordem de inscrição foi o que validou o preenchimento das vagas ociosas.

O público-alvo do curso foi composto por pessoas de diferentes grupos: estudantes da educação básica, de graduação e pós-graduação; professores da educação básica, da graduação e da pós-graduação; técnicos-administrativos da UESB e, finalmente, pessoas de associações comunitárias e de sindicatos. Essa diversidade enriqueceu a experiência docente e discente, pois cada um compartilhava sua visão de mundo diante das letras, dos ritmos, das discussões transversais que cada música trazia. A seguir, discutimos sobre a metodologia utilizada, a avaliação proposta e nas considerações finais, se os objetivos do curso se consolidaram conforme havíamos planejado.

\section{Metodologia}

O curso foi organizado em dez encontros, com duas horas de duração cada. Foram empregadas vinte horas na preparação do curso e das aulas, e outras vinte horas foram dedicadas à divulgação e inscrição dos candidatos interessados. Tudo foi feito online, por meio de formulários Google e com divulgação no site institucional da universidade e nas redes sociais.

Revista Extensão \& Cidadania, v. 9, n. 16, p. 112-122, jul./dez. 2021. 


\section{Figura 1 - Banner do Google Sala de Aula}
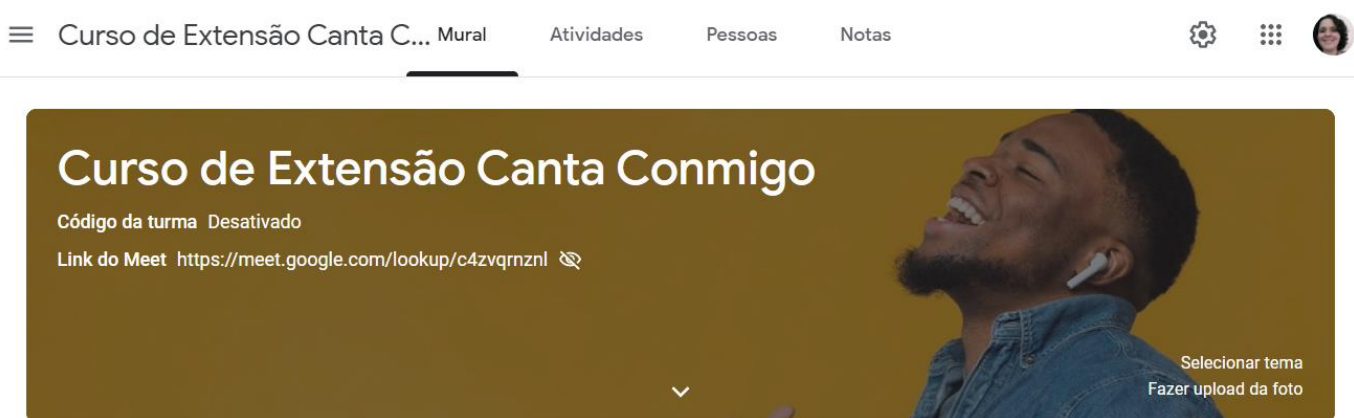

Próximas atividades

Nenhuma atividade para a

(1)

Escreva um aviso para sua turm

$\rightleftarrows$ próxima semana

Fonte: Elaborado pela autora (2020).

As aulas aconteceram na plataforma Google Meet, todas eram gravadas e, posteriormente, postadas na sala do Google Sala de Aula (Figura 1), à qual os alunos tinham acesso para possíveis consultas. Os materiais relacionados ao curso foram postados no Google Sala de Aula, onde criamos uma midiateca com diferentes materiais relacionados com as canções trabalhadas: videoclipes, artigos, documentários, exercícios etc., como é possível observar na imagem da Figura 2, com os materiais acerca da canção "Clandestino", de Manu Chao:

Figura 2 - Sessão 2 do curso (midiateca)

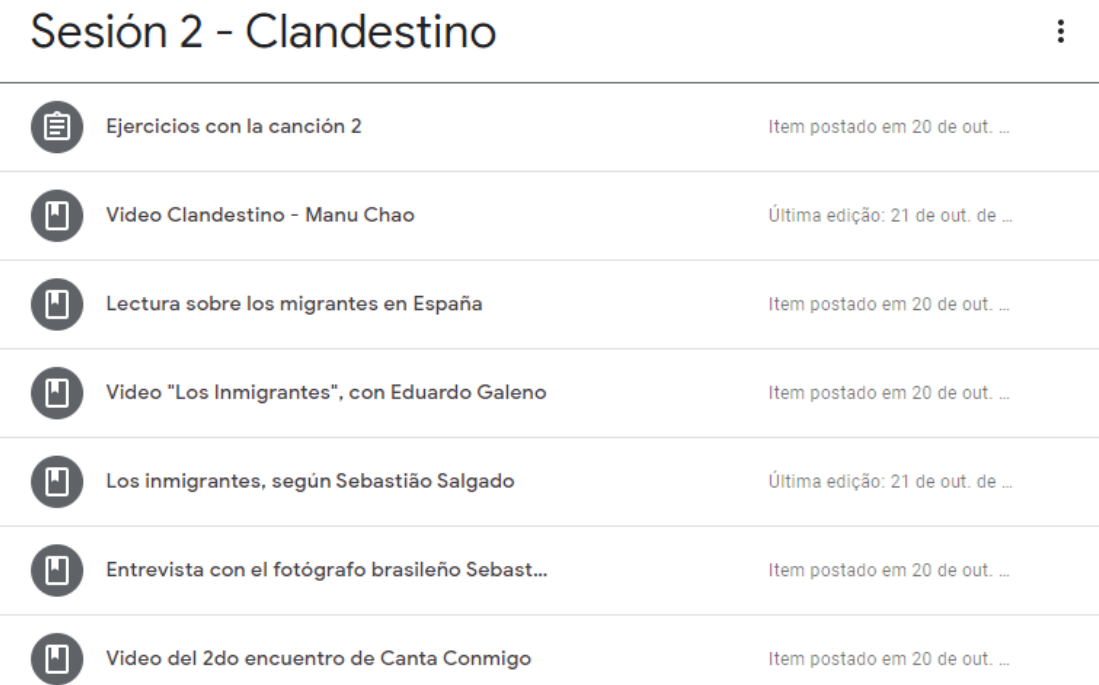

Fonte: Elaborado pela autora (2020).

Revista Extensão \& Cidadania, v. 9, n. 16, p. 112-122, jul./dez. 2021.

ISSN 2319-0566 DOI: 10.22481/recuesb.v9i16.8690 
Cada encontro do curso contava com a apresentação de uma nova canção, o que nos deu um total de dez sessões. As canções foram escolhidas segundo a sequência dos conteúdos a serem explorados, os quais evoluíram do nível A1 ao nível A2 do Marco Comum Europeu de Referência (MCER). Assim, era natural que a escolha se desse pelo crivo da docente, e não segundo os gostos e desejos dos/das estudantes inscritos. A complexidade dos temas gramaticais e do vocabulário cresceu paulatinamente, à medida que as canções eram apresentadas. A seguir, apresentamos a lista das canções trabalhadas, segundo sua ordem cronológica, bem como os cantores/grupos e seus respectivos países de origem:

\author{
1. Con los años que me quedan, Gloria Estefan (Cuba) \\ 2. Clandestino, Manu Chao (Espanha) \\ 3. La Llorona, Natalia Lafourcade (México) \\ 4. Bonito, Jarabe de Palo (Espanha) \\ 5. Corazón espinado, Maná e Santana (México) \\ 6. La cumbia del mole, Lila Downs (México) \\ 7. La Lola, Café Quijano (Espanha) \\ 8. Brillante sobre el mic, Fabiana Cantilo (Argentina) \\ 9. Dos gardenias, Ibrahim Ferrer (Cuba) \\ 10. Despacito, Luis Fonsi (Porto Rico)
}

Diversos exercícios foram preparados para explorar variados conteúdos presentes nas letras, tais como: fonética, léxico, tempos verbais, expressões idiomáticas, conteúdos culturais acerca do cantor ou grupo e de seu país de origem, informação sobre o estilo musical etc. Normalmente, o material começava com a letra da canção, seguida pela fonética, depois o vocabulário, a gramática e, por fim, tínhamos informação sobre o cantor/a cantora e o ritmo. Às vezes, tínhamos uma sessão de interpretação de leitura, pois algumas canções têm letras mais poéticas, ou ofereciam expressões idiomáticas que valia a pena conhecer mais detidamente. Além disso, discutíamos temas transversais propostos nas letras - tais como: a imigração ilegal na Espanha, os alimentos autóctones de alguns países americanos, o dia dos Mortos no México, a importância da música em Cuba, entre outros.

Nos exercícios da sessão 9, por exemplo, depois de ouvir o bolero cubano "Dos gardenias", trabalhamos a formação do singular e do plural, bem como o uso dos artigos definidos em espanhol; em seguida, vimos os números; depois, em um terceiro exercício, aprendemos o futuro imperfecto, cujas formas nos haviam sido oferecidas pela canção. Por fim,

Revista Extensão \& Cidadania, v. 9, n. 16, p. 112-122, jul./dez. 2021. 
outro exercício trabalhava os adjetivos posesivos; a atividade finalizava com perguntas de compreensão de leitura e com a biografia do cantor cubano Ibrahim Ferrer.

Em cada encontro, ouvir a canção preparada e realizar as atividades proporcionava aos/às estudantes o contato com elementos linguísticos, culturais e comunicacionais que seguramente lhes aproximou da língua de Miguel de Cervantes e de Eduardo Galeano. Todos eram convidados a participar, em todas as aulas, e essa prática gerou uma atitude de confiança e envolvimento. Depois de alguns encontros, a participação tornou-se espontânea e os/as estudantes se mostravam muito motivados.

Apesar de as canções serem escolhidas previamente e essa escolha não passar pela intervenção dos/das estudantes, eles/elas se sentiram identificados pessoal e culturalmente com as canções, o que também facilitou a sua aquisição linguística. A relação entre os conteúdos do curso e a aquisição de uma língua são discutidas por Krashen (1987), quem nos diz que ela não requer um uso exaustivo de exposição às regras da gramática de forma consciente ou a repetição descontextualizada. Ao contrário, a aquisição de uma língua passa pelo contexto significativo e o input se dá de maneira compreensível. Ao entrar em contato com as letras das canções e seu contexto, ao experenciar as emoções proporcionadas por elas, seguramente os/as estudantes puderam realizar a aquisição linguística, mesmo que parcialmente.

À medida que o curso avançava e os temas gramaticais, culturais e comunicativos eram trabalhados, os/as estudantes se tornavam naturalmente mais participativos/as. $\mathrm{O}$ ambiente relaxado das aulas com canções oferece a possibilidade de criar as condições ideais para aprender com prazer e alegria, num contexto significativo e de confiança mútua entre professora e estudantes, como nos relata Jiménez et al.:

Varios psicólogos y lingüistas han tratado de demostrar la enorme influencia de la música en la formación del individuo: como precedente y ayuda al desarrollo del habla (Livingston, 1973), como posible manifestación o activador del teórico mecanismo de adquisición de las lenguas (Krashen, 1983), como agente de relajación y agitación, como factor de integración de los individuos en alguna parte de la sociedad, de armonía con uno mismo y con el grupo, cultura, patria, religión, revolución, etcétera, tanto como por su similitud con el lenguaje egocéntrico de que habla Piaget (1923) en referencia al placer de escucharse. (JIMÉNEZ; MARTÍN; PUIGDEVALLI, 1999, p. 132 apud GARCÍA, 2013, p.1-2)

Infelizmente, por estarmos online, não era possível cantarmos juntos, mas cada um/uma de nós cantava ao seu modo, durante ou depois de cada encontro e, seguramente, a sonoridade do espanhol, seus muitos ritmos, palavras e sotaques passaram a integrar o cotidiano de quem integrou o curso Canta Conmigo.

Revista Extensão \& Cidadania, v. 9, n. 16, p. 112-122, jul./dez. 2021. 


\section{Avaliação}

No final do curso, foi proposta uma avaliação realizada por meio de um formulário Google, a qual foi enviada aos/às estudantes frequentes ao curso, por e-mail. A finalidade era observar, junto aos/às estudantes, se os objetivos do curso se haviam cumprido, bem como a percepção que eles/elas haviam tido do curso realizado cem por cento online e da metodologia utilizada. Além disso, queríamos obter opiniões e sugestões a fim de poder aperfeiçoar os aspectos tratados na avaliação, para uma futura edição do Canta Conmigo.

Conforme Cervi (2017 apud SANTOS et al. 2020), as questões fechadas consistem em perguntas com respostas pré-definidas; já às questões abertas, a partir da pergunta formulada, o entrevistado pode dar sua própria resposta de forma espontânea. As questões foram elaboradas através de parâmetros de avaliação do curso estabelecidas pela coordenação. As questões propostas têm suas respostas elencadas a seguir, o questionário de avaliação começa com os dados pessoais dos estudantes.

- Quase 53\% dos estudantes estão na faixa etária de 31 a 40 anos de idade.

- A maioria da turma $(76,5 \%)$ é composta por pessoas do sexo feminino.

- Sobre ter vínculo com a UESB, quase $60 \%$ dos estudantes pertenciam à comunidade acadêmica da UESB, seja como estudante ou servidor. O restante da turma pertence à comunidade externa.

- Sobre a escolaridade, havia uma estudante da educação básica; alguns estudantes de graduação; alguns estudantes de pós-graduação (mestrado e doutorado); professores da UESB; professores da educação básica; técnicos-administrativos da UESB; e membros da comunidade externa à universidade. Foram 40 pessoas selecionadas para o curso, mas somente 26 frequentaram até o final.

- Aproximadamente $70 \%$ da turma já havia tido algum contato com a língua espanhola. Pouco mais de $23 \%$ nunca havia tido contato algum.

- A totalidade dos/das estudantes declarou que as suas expectativas acerca do curso foram atendidas.

- A totalidade dos/das estudantes declarou que a metodologia utilizada pela docente nas aulas é excelente.

- A totalidade dos/das estudantes declarou que os materiais e exercícios utilizados durante as aulas foram excelentes.

Revista Extensão \& Cidadania, v. 9, n. 16, p. 112-122, jul./dez. 2021. 
- A totalidade dos/das estudantes declarou que a abordagem e o domínio dos conteúdos pela docente são excelentes.

- A totalidade dos/das estudantes declarou que avaliam a docente como excelente.

- A totalidade dos/das estudantes declarou que o curso ofereceu conhecimentos significativos para a sua formação pessoa, acadêmica e/ou profissional.

- $70 \%$ dos/das estudantes consideraram satisfatória a duração do curso. Aproximadamente 18\%, não.

- A totalidade dos/das estudantes declarou que teria interesse em fazer outro curso ligado à língua espanhola.

- Uma das últimas perguntas tratava sobre os sentimentos dos estudantes antes e após a realização do curso, e todas foram positivas.

-Também escreveram sobre os aspectos positivos do curso, e comentaram sobre a metodologia empregada, o dinamismo das aulas, a cultura etc.

-Também foi perguntado em que poderíamos melhorar, ao que responderam que um curso de maior duração ou uma versão presencial seriam interessantes.

A avaliação foi um instrumento que serviu de observação do que foi aprendido, de como avançamos mesmo em meio às condições adversas da pandemia, da capacidade que temos para construir laços afetivos com os/as estudantes mesmo à distância e, também, daquilo em que podemos melhorar e nos aperfeiçoar. Ela será tomada como referência para uma futura edição do Canta Conmigo.

\section{Considerações finais}

Durante o curso, o interesse pela língua e pela(s) cultura(s) ligadas ao espanhol foi alcançado, bem como a aproximação e o reconhecimento de diversas estruturas gramaticais. Os alunos desenvolveram uma maior consciência sobre a diversidade intrínseca à língua espanhola e aos diversos países hispanófonos, para além daquela que já traziam e que os havia atraído para as aulas.

O conhecimento de uma língua estrangeira propicia ao aprendiz uma nova gama de habilidades que poderão auxiliá-lo em suas práticas acadêmicas e laborais, bem como em sua qualidade de vida, ampliando seu olhar sobre as culturas e as relações humanas. Isso se dá notadamente com a língua espanhola, que é falada por mais de 400 milhões de pessoas em todo o mundo e em cinco continentes.

Revista Extensão \& Cidadania, v. 9, n. 16, p. 112-122, jul./dez. 2021. 
A realização desse curso de extensão reforça a necessidade de discutir sobre a importância da língua espanhola para os brasileiros. Num país cercado por vizinhos hispanófonos, falar e compreender espanhol torna-se um instrumento de integração cultural e sociopolítica.

No meio acadêmico, a leitura de diversos textos escritos em espanhol é de grande valia para a formação inicial e continuada de discentes e docentes, bem como de acesso a discursos, teorias, autores de diversas épocas e escolas. Promover uma aproximação com a língua espanhola de forma lúdica torna a aprendizagem mais prazerosa e fluida, o que facilita o trabalho do professor e estimula aquele/aquela que a aprende. Gostaríamos de continuar oferecendo o curso em semestres futuros, pois reconhecemos a importância de espaços de aprendizado e partilha cultural da língua espanhola.

\section{Referências}

BRASIL. Lei $\mathbf{n}^{0}$ 11.161, de 5 de agosto de 2005. Dispõe sobre o ensino da língua espanhola. Brasília, DF, 2005.

GARCÍA, Juan Robisco. La explotación didáctica de las canciones en la clase de español. Nova Déli: Instituto Cervantes de Nova Déli, 2013.

KRASHEN, Stephen D. Principles and practice in second language acquisition. New York: Prentice-Hall International, 1987.

MOLEIRO, Marta Sofia Rodrigues dos Santos. A exploração da canção na aula de espanhol como língua estrangeira. 2011. 223 f. Dissertação (Mestrado em Ensino) Universidade de Lisboa, Universidade de Lisboa, Lisboa, 2011.

SANTOS, Viviane V. dos; BEGA, Maria Tarcisa S.; COSTA, Eder Augusto R.; MACIEL, Barbara R.; LOSS, Valentina F.; BRANTES, Mariane; GOMES, Ariely T.; PALMARES, Jonas. Introdução às políticas públicas: relatos de experiência sobre um curso de extensão. Revista Extensão em Foco, Curitiba, n. 20, p. 54-70, jan./jul. 2020.

Recebido: 10.05.2021

Aceito: 04.08.2021

This work is licensed under a Creative Commons Attribution 4.0 International License.

Este trabalho está licenciado com uma Licença Creative Commons - Atribuição 4.0

Revista Extensão \& Cidadania, v. 9, n. 16, p. 112-122, jul./dez. 2021. 